\title{
TO COMPARE THE EFFECT OF LOW DOSE ATRACURIUM VERSUS LOW DOSE ROCURONIUM ON QUALITY OF INTUBATION IN CHILDREN UNDERGOING ADENOTONSILLECTOMIES.
}

1. FCPS Anaesthesiology Consultant Anesthetist King Khalid Hospital, Saudi Arabia.

2. FCPS, MCPS (Anaesthesiology) Head

Department of Anesthesia/ICU/Pain Management

Seikh Zayed Hospital, Lahore.

3. FCPS (Cardiology)

Assistant Professor

Department of Cardiology University Medical \& Dental College, Faisalabad

4. MCPS (Anaesthesiology) Resident

Department of Anaesthesia King Khalid Hospital, Saudi Arabia

5. FCPS (Anaesthesiology) Specialty Doctor

Daren't Valley Hospital, Dartford. DA2 8DA, UK

6. FCPS (Cardiology)

Senior Registrar

Wazirabad Institute of Cardiology, Wazirabad.

Correspondence Address:

Dr. Muhammad Ahmad Khan

King Khalid Hospital, Saudi Arabia.

ahmadchishtik@gmail.com

Article received on:

02/03/2019

Accepted for publication:

26/09/2019
Muhammad Ahmad Khan', Syed Sajjad Kazmi², Shakeel Ahmad ${ }^{3}$, Tariq Mahmood ${ }^{4}$, Motsim Sheraz Naeem Asghar ${ }^{6}$

ABSTRACT... Objectives: We conducted this study by comparing low dose of atracurium with low dose rocuronium to see their effects on quality of endotracheal intubation and recovery characteristics as these both agents are widely available and practiced in anesthesia. Study Design: This is prospective, randomised, double blind clinical trial. Setting: ENT operating room of King Khalid Hospital, Saudi Arabia. Period: From January 2018 to April 2018. Material \& Methods: In this study, 80 elective paediatric patients planned for adenotonsillectomies operations were randomly selected. Anesthesia was induced by using fentanyl $2 \mathrm{mcg} / \mathrm{kg}$, propofol $2 \mathrm{mg} / \mathrm{kg}$. Patients were divided into two groups, group A and group R. Group A received $0.3 \mathrm{mg} / \mathrm{kg}$ atracurium and group $\mathrm{R}$ received $0.3 \mathrm{mg} / \mathrm{kg}$ rocuronium to facilitate endotracheal intubation. Sevoflurane was used for maintenance of anaesthesia in 50 percent oxygen and 50 percent nitrous oxide. Dexamethasone $0.1 \mathrm{mg} / \mathrm{kg}$ was administered in all patients to reduce post operative airway oedema and prophylaxis for PONV. Quality of intubation was assessed and graded as; Good: Jaw and vocal cords relaxed and no patient movement/coughing upon laryngoscopy/intubation. HR and BP within 20 percent range. Fair: Jaw and vocal cords relaxed but patient show body movement/coughing upon laryngoscopy/intubation HR and BP within 20 percent range. Poor: Jaw is partially relaxed, vocal cords moving/closed and patient shows body movement/coughing upon laryngoscopy/intubation. HR and BP beyond 20 percent range. Results: There were 40 patients in each group. 37.5 percent were operated for tonsillectomy, 32.6 percent for adenotonsillectomy and 30.1 percent for tonsillectomy and there was no statistically significant difference regarding type of operation $(P=0.861)$. Age $(P=0.321)$, sex $(P=0.370)$ and weight $(P=0.243)$ in both groups. Grades of intubation quality were comparable and same in both groups $(P=0.710)$. Extubation and recovery was also normal and same in both groups. Conclusion: Low doses of atracurium or low dose of rocuronium can be safely used for good quality of endotracheal intubation and smooth recovery in elective paediatric patients coming for short ENT operations.

Key words: $\quad$ Adenotonsillectomy, Endotracheal Intubation, Low Dose Atracurium, Low Dose Rocuronium.

Article Citation: Khan MA, Kazmi SS, Ahmad S, Mahmood T, Sheraz M, Asghar N. To compare the effect of Low Dose Atracurium versus Low Dose Rocuronium on quality of intubation in children undergoing adenotonsillectomies. Professional Med J 2019; 26(12):2141-2145. DOI: 10.29309/TPMJ/2019.26.12.3342

\section{INTRODUCTION}

Anaesthesia concerns for adenotonsillectomy procedures is to secure airway by endo-tracheal intubation. The choice of muscle relaxant is by early onset of action and short-er duration of action. Anesthesia practice varies for this concern due to the availability of muscle relaxants and individual preferences. Adenotonsillectomies are very com-mon in paediatric population. As these are shorter in operating duration so the choice of muscle relaxant should be with early in onset and shorter in duration of action. Op-erations in oral cavity have risk of aspiration so it is preferred to secure airway with en-dotracheal intubation. Inhalational agents in children produces vocal cord relaxation and making it possible to do endotracheal intubation without muscle relaxants but it requires longer induction time and more depth of anesthesia.

Endotracheal intubation can be done with or without use of neuromuscular blocking agents. ${ }^{1}$ LMA can also be used for adenotonsillectomies ${ }^{2,3}$ but majority of anaesthe-tist prefer to secure 
airway with endotracheal tube. There is a wide selection of neu-romuscular blocking agents. Some anaesthetist prefer succinylcholine due to its early onset and short duration of action but others has reservation about its use in elective paediatric population.

Atracurium and rocuronium are widely available in anaesthesia practice and can be safely used in paediatric population. Both drugs are non-depolarizing muscle relaxant and act on neuromuscular junction to produce muscle relaxation required for ease of endotracheal intubation and surgical muscle relaxation. Both drugs are intermediate in their duration of action and can be easily reversed at the end of surgery although their metabolic pathway is different. Rocuronium has the advantage that it can be reversed early with new reversal agent called sugammadex. Both if used in normal recommended doses, may have delayed extubation or recovery in short surgical procedures like adenotonsillectomies.

Keeping in mind about short duration of adenotonsillectomies, we conducted this study to compare the low dose of atracurium with low dose of rocuronium for good quality of endotracheal intubation, smooth extubation and quick recovery.

\section{METHODS}

This prospective, randomised, double blind clinical trial was conducted from January 2018 to April 2018 in ENT operating room of King Khalid Hospital, Saudi Arabia. In-formed consent was taken from the parents of the children included in this study and got approval from the institutional review committee. 80 ASA 1 and II patients planned for elective adenotonsillectomies were included in study. Children coming for emergency operations, anticipated difficult airway, allergic to any study drugs, refusal for study consent were excluded from this study.

Sample size was calculated by taking estimated frequency of good intubating condi-tion in $58 \%$ patients receiving atracurium and in $16 \%$ patients receiving rocuronium after 60 seconds of administration of drugs 4 , at power of test $80 \%$ and level of signifi-cance $5 \%$. The calculated sample size was 25 patients in each group. We took 40 pa-tients in each group to minimise biases in study.

Patients were seen in anaesthesia clinic for preoperative assessment. After doing clinical assessment and reviewing labs, they were accepted for surgery. On the day of sur-gery, all patients were reviewed and explained about the study. If they accept then in-formed consent was taken. All patients were divided into two groups with random se-lection and the concerned anaesthetist was kept blind about the type of study group. Group A belonged to atracurium and group $\mathrm{R}$ was rocuronium.

In operating room after preparing drugs and equipments, standard monitors were ap-plied to all patients and recorded baseline vital sign reading. Patency of intravenous cannula was assures by starting intravenous fluid. All patients were pre-oxygenated. Both groups were given intravenous fentanyl $2 \mathrm{mcg} / \mathrm{kg}$ and propofol 2 $\mathrm{mg} / \mathrm{kg}$ at induc-tion. Once patient was sleeping, mask ventilation was instituted for 3 minute with sevoflurane at 3 percent in 100 percent oxygen. After 3 minutes, laryngoscopy was done to assess the ease of intubation. Quality of intubation was assessed according to the four-point scale of Cooper et al. and graded as;

Good: Jaw and vocal cords relaxed and no patient movement/coughing upon laryn-goscopy/ intubation. HR and BP within 20 percent range.

Fair: Jaw and vocal cords relaxed but patient show body movement/coughing upon laryngoscopy/ intubation HR and BP within 20 percent range.

Poor: Jaw is partially relaxed, vocal cords moving/closed and patient shows body movement/coughing upon laryngoscopy/ intubation. HR and BP beyond 20 percent range.

Vital signs were recorded immediately after endotracheal intubation and then after every 5 minute interval. Anesthesia was maintained 
with sevoflurane 2 percent in 50 percent oxygen and 50 percent nitrous oxide and vital signs were kept within 20 per-cent range of baseline. Dexamethasone $0.1 \mathrm{mg} / \mathrm{kg}$ was administered in all patients to reduce post operative airway oedema and prophylaxis for PONV. At the end of surgery all patients were reversed by using neostigmine $0.03 \mathrm{mg} / \mathrm{kg}$ and atropine $10 \mathrm{mcg} / \mathrm{kg}$ upon return of spontaneous breathing. Extubation was done once patient was awake, had adequate spontaneous breathing, maintaining normal $\mathrm{SpO} 2$ and EtCO2, normal vital signs and no significant bleeding from the surgical site.

Extubation was noted as normal if it was within expected time and delayed if it was more than expected time. After extubation, once patient was stable then shifted to re-covery room. Same standard recovery room care was provided to all patients. Recov-ery time was also noted as normal if it was within expected time and delayed if it was more than expected time.

Once the patients were fully awake, stable and fulfilling the required recovery room pa-rameters then were transferred to the concerned unit.

\section{Variable Measured}

The primary outcome of our study was to see the quality of endotracheal intubation by measuring the grades of intubation. Other measures were the timing of extubation and recovery characteristics.

\section{Statistical Analysis}

Data of all variables, types of operations, quality of intubation, extubation time, recov-ery time, age, weight and sex were analysed by using SPSS of IBM and $P$ value $>0.05$ was taken as statistically non significant. Chi-Square test was applied to analyse quali-tative data and Student's t-test was used for quantitative data.

\section{RESULTS}

There were 40 patients in each group. 37.5 percent were operated for tonsillectomy, 32.6 percent for adenotonsillectomy and 30.1 percent for tonsillectomy and there was no significant difference regarding the type of operation between 2 groups $(P=0.861)$. Age $(P=0.321)$, sex
$(P=0.370)$ and weight $(P=0.243)$ were also similar in both groups. Grades of intubation quality were comparable and same in both groups $(P=0.710)$. Ex-tubation and recovery was also normal and same in both groups.

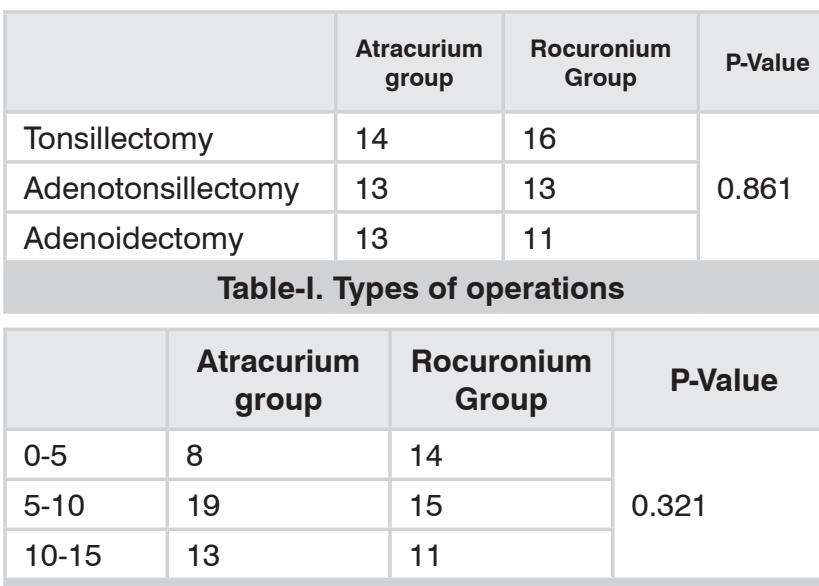

Table-II. Patient parameters-Age groups in years

\begin{tabular}{|l|c|c|c|}
\hline & $\begin{array}{c}\text { Atracurium } \\
\text { group }\end{array}$ & $\begin{array}{c}\text { Rocuronium } \\
\text { Group }\end{array}$ & P-Value \\
\hline Male & 23 & 19 & 0.370 \\
\hline Female & 17 & 21 & \\
\hline
\end{tabular}

Table-III. Patient parameters-Sex

\begin{tabular}{|c|c|c|}
\hline $\begin{array}{c}\text { Atracurium } \\
\text { Group }\end{array}$ & $\begin{array}{c}\text { Rocuronium } \\
\text { Group }\end{array}$ & P-Value \\
\hline 2.12 & 1.92 & 0.243 \\
\hline
\end{tabular}

Table-IV. Patient parameters-Weight groups in kg

\begin{tabular}{|l|c|c|c|}
\hline Good & $\begin{array}{c}\text { Atracurium } \\
\text { Group }\end{array}$ & $\begin{array}{c}\text { Rocuronium } \\
\text { Group }\end{array}$ & P-Value \\
\hline Fair & 33 & 30 & \\
\hline Poor & 4 & 6 & 0.710 \\
\hline
\end{tabular}

Table-V. Quality of intubation

\begin{tabular}{|l|c|c|}
\hline & $\begin{array}{c}\text { Atracurium } \\
\text { Group }\end{array}$ & $\begin{array}{c}\text { Rocuronium } \\
\text { Group }\end{array}$ \\
\hline Normal & 40 & 40 \\
\hline Delayed & 0 & 0 \\
\hline & Table-VI. Extubation \\
\hline Normal & $\begin{array}{c}\text { Atracurium } \\
\text { Group }\end{array}$ & $\begin{array}{c}\text { Rocuronium } \\
\text { Group }\end{array}$ \\
\hline Delayed & 40 & 40 \\
\hline & 0 & 0 \\
\hline
\end{tabular}




\section{DISCUSSION}

Airway is a key concern in adenotonsillectomy operations due to the shared airway. Airway securing tubes can be easily dislodged while doing surgery. There is risk of blood and secretions aspiration during and after surgery. Children commonly suffers from hypertrophied or infected adenoids/tonsils or both. It results in fever, airway obstruction, ear/sinuses/chest infections and other complications. It badly affects the daily life activities. Initially it is treated medically but repeated infections or associated with complication needs surgical interventions. ${ }^{5}$

Some studies have shown the use of reinforced laryngeal mask airway (LMA) as alternative technique to secure airway in tonsillectomy without use of muscle relaxant and offering good surgical view. ${ }^{6}$ But its use can be associated with aspiration or airway obstruction during tonsillectomy. ${ }^{7,8}$

Endotracheal intubation is a preferred and widely practiced way of general anesthesia for adenotonsillectomy in children. Endotracheal intubation can be performed with or without muscle relaxant in paediatric population. ${ }^{9}$ Khan FA et al. ${ }^{10}$ conducted study and found that adenotonsillectomy can be done on spontaneous or controlled breathing. Masoom A et al. ${ }^{11}$ studied that adenotonsillectomy can be performed safely as day case procedure. Both depolarizing and non-depolarising neuromuscular blocking agents are practiced to facilitate endotracheal intubation. ${ }^{12,13}$ As most of the time the duration of a adenotonsillectomy is short so it is preferred to use muscle relaxant having short duration of action. Choice of muscle relaxant use depends upon the availability of drug and individual preferences.

Atracurium and rocuronium are safe and commonly used muscle relaxants. Both are intermediate acting drugs. Rocuronium in comparison to atracurium has shown to be early in onset and shorter in duration. ${ }^{14-16}$ Miguel RV et $\mathrm{al}^{17}$ showed that with desflurane anesthesia, low dose of $0.45 \mathrm{mg} / \mathrm{kg}$ rocuronium was better in onset and short duration in comparison to 0.5 $\mathrm{mg} / \mathrm{kg}$ dose of atracurium. Nada $\mathrm{EN}^{18}$ has similar finding of ease of LMA insertion and reduced required dose of propofol by using low dose 0.15 $\mathrm{mg} / \mathrm{kg}$ of rocuronium. Ross AK et al ${ }^{19}$ found that recovery characteristics of regular dose $0.6 \mathrm{mg} /$ $\mathrm{kg}$ and low dose $0.45 \mathrm{mg} / \mathrm{kg}$ of rocuronium were comparable but intubation conditions were better with $0.6 \mathrm{mg} / \mathrm{kg}$.

Whalley DG et $\mathrm{al}^{20}$ studied that in comparison to atracurium, rocuronium had better profile regarding onset, side effects, intubation condition but recovery was slower.

Our study has shown that reduced doses $(0.3 \mathrm{mg} /$ $\mathrm{kg}$ ) of atracurium and rocuronium can be safely used in paediatric patients for adenotonsillectomy. Quality of intubation was good in majority of patients. There was no delay in extubation at the end of surgery and patients were smoothly discharged from the recovery room.

\section{CONCLUSION}

Low doses of atracurium and rocuronium have comparable results regarding good quality intubation, early extubation, smooth recovery and early discharge from recovery room. Both of these drugs can be safely used for children undergoing adenotonsillectomies.

Copyright@ 26 Sep, 2019.

\section{REFERNCES}

1. Batra YK1, Al Qattan AR, Ali SS, Qureshi MI, Kuriakose $D$, Migahed A. Assessment of tracheal intubating conditions in children using remifentanil and propofol without muscle relaxant. Paediatr Anaesth. 2004 Jun; 14(6):452-6.

2. Peng A1, Dodson KM, Thacker LR, Kierce J, Shapiro $\mathrm{J}$, Baldassari CM. Use of laryngeal mask airway in pediatric adenotonsillectomy. Arch Otolaryngol Head Neck Surg. 2011 Jan; 137(1):42-6.

3. Sierpina DI, Chaudhury $H$, Walner DL, Villines D, Schneider K, Lowenthal M, Aronov Y. Laryngeal mask airway versus endotracheal tube in pediatric adenotonsilletomy. Laryngoscope. 2012 Feb; 122(2):429-35. 
4. Mitra M, Nag A, Ganguly T, Kar SK, Lahiri S. Quality of Laryngoscopic View and Rapidity of Development of Intubating Conditions after Atracurium, Vecuronium and Rocuronium: A Randomized Controlled Study. J Bioequiv Availab. 2016; 8:128-33.

5. Ingram DG, Friedman NR. Toward Adenotonsillectomy in Children: A Review for the General Pediatrician. JAMA Pediatr 2015; 169:1155.

6. Williams PJ, Bailey PM. Comparison of the reinforced laryngeal mask airway and tracheal intubation of adeno-tonsillectomy. Br J Anaesth 1993; 70:30-3.

7. Webster AC, Morley-Forster PK, Dain S, et al. Anesthesia for adenotonsillectomy: A comparison between tracheal intubation and the laryngeal mask airway. Can J Anaesth 1993; 40:1171-7.

8. Heath ML, Sinnathamby SW. The reinforced laryngeal mask airway for adenotonsillectomy. $\mathrm{Br} \mathrm{J}$ Anaesth 1994; 72:728, 729.

9. Simon L1, Boucebci KJ, Orliaguet G, Aubineau JV, Devys JM, Dubousset AM. A survey of practice of tracheal intubation without muscle relaxant in paediatric patients. Paediatr Anaesth. 2002 Jan; 12(1):36-42.

10. Khan FA1, Memon GA. Comparison of spontaneous with controlled mode of ventilation in tonsillectomy. Paediatr Anaesth. 2001 Mar; 11(2):185-90.

11. Masoom A1, Akhtar S, Humayun HN, Ikram M. Daycare adeno-tonsillectomy: Is it safe in developing countries? J Pak Med Assoc. 2012 May; 62(5):458-60.

12. Barve $M$, Sharma R. Comparison of intubating conditions and time course of action of rocuronium bromide and succinylcholine in paediatric patients. Indian J Anaesth. 2002; 46:465-8.
13. Kwon MA, Song J, Kim JR. Tracheal intubation with rocuronium using a "modified timing principle” Korean J Anesthesiol. 2013; 64:218-22.

14. Xue F1, Zhang Y, Liao X, Liu J, An G. A comparative study of the dose-response and time course of recovery of atracurium and rocuronium. Chin Med $\mathrm{J}$ (Engl). 2000 Nov; 113(11):1019-21.

15. Ribeiro FC1, Scheiber G, Marichal A. Comparison of time course of neuromuscular blockade in young children following rocuronium and atracurium. Eur $\mathrm{J}$ Anaesthesiol. 1998 May; 15(3):310-3.

16. Hans P1, Brichant JF, Franzen A, Faleres X, Lamy M. Comparison of neuromuscular block of atracurium and rocuronium in adults. Acta Anaesthesiol Belg. 1996; 47(2):53-8.

17. Miguel RV, Soto R, Dyches P. A double blind, randomised comparison of low dose rocuronium and atracurium in a Desflurane anesthetic. $J$ Clin Anesth. 2001 Aug; 13(5):325-29.

18. Nada EN. Efficacy of low-dose rocuronium in reducing induction dose of propofol in classic laryngeal mask airway insertion in one day case surgery. Research and Opinion in Anesthesia \& Intensive Care 2018, 5:341-346

19. Ross AK1, Dear GL, Dear RB, Margolis JO, Ginsberg $B$. Onset and recovery of neuromuscular blockade after two doses of rocuronium in children. J Clin Anesth. 1998 Dec; 10(8):631-5.

20. Whalley DG1, Maurer WG, Knapik AL, Estafanous FG. Comparison of neuromuscular effects, efficacy and safety of rocuronium and atracurium in ambulatory anaesthesia. Can J Anaesth. 1998 Oct; 45(10):954-9.

\begin{tabular}{|c|l|l|l|}
\multicolumn{4}{|c|}{ AUTHORSHIP AND CONTRIBUTION DECLARATION } \\
\hline Sr. \# & Author(s) Full Name & \multicolumn{1}{|c|}{ Contribution to the paper } & Author(s) Signature \\
\hline 1 & M. Ahmad Khan & $\begin{array}{l}\text { Conceived, designed, data } \\
\text { analysis, and editing of manuscript. } \\
\text { Helped in writing the manuscript } \\
\text { and did review and approved the } \\
\text { final version for publication. } \\
\text { Did data collection. }\end{array}$ \\
\hline 2 & Syed Sajjad Kazmi & Sid data collection. \\
\hline 5 & Shakeel Ahmad & Tariq Mahmood & $\begin{array}{l}\text { Dotsim Sheraz } \\
\text { Did review and helped a lot in } \\
\text { finalizing the manuscirpt. } \\
\text { Did review and helped a lot in } \\
\text { finalizing the manuscirpt. }\end{array}$ \\
\hline 6 & Naeem Asghar & \\
\hline
\end{tabular}

